\title{
Zebra finch cell lines from naturally occurring tumors
}

\author{
Yuichiro Itoh • Arthur P. Arnold
}

Received: 7 November 2010 / Accepted: 26 January 2011 / Published online: 27 February 2011 / Editor: J. Denry Sato

(C) The Author(s) 2011. This article is published with open access at Springerlink.com

\begin{abstract}
The zebra finch (Taeniopygia guttata) has been intensively studied in many research fields including neuroscience, behavioral neurobiology, and evolution of the genome. Although numerous molecular and genomic resources are available for this model species, immortalized cell lines have been lacking. We have established two zebra finch cell lines derived from spontaneous tumors. ZFTMA is a tetraploid female cell line and G266 as a diploid male cell line. These first zebra finch cell lines should facilitate development of research on this model species.
\end{abstract}

Keywords Zebra finch $\cdot$ Cell line · Immortalized $\cdot$ Male Female

\section{Introduction}

The zebra finch, an oscine songbird (order Passeriformes), has been extensively studied as a model for the behavioral neurobiology of learning, the role of adult neurogenesis, the neural basis of sensory perception and cognition, sexual differentiation of the brain, and evolution of the genome. The study of songbirds has contributed to numerous fields in neurobiology, neuroendocrinology, and evolution. (Ziegler and Marler 2004). The zebra finch was the second avian genome to be sequenced (Warren et al. 2010). Although numerous genomic resources are now available for this important animal model, there have been no available

\footnotetext{
Y. Itoh $(\bowtie) \cdot$ A. P. Arnold

Department of Integrative Biology and Physiology, University of California,

UCLA 610 Charles E. Young Drive South, Room 1146,

Los Angeles, CA 90095-1606, USA

e-mail: yitoh@ucla.edu
}

immortalized cell lines for intensive molecular and cell biology research including transfection of specific genes or recombinant protein expression.

To establish a valuable cell line resource, we isolated cells from naturally occurring tumorous tissues. Although such tumors are rare, over the years, we found two birds with tumor-like abnormal tissue in our zebra finch colony in Los Angeles. One female bird (Brown 264), which we established ZFTMA cell line from, had a left thigh that was almost 20-30 times larger than the right one. This bird had complete female plumage and normal ovary, but its liver was almost ten times larger and kidney size was also about six times larger than normal. Another bird (Gray 266), which we established G266 cell line from, had a tumor-like tissue under the skin of his forehead. This bird had male plumage and normal testis, and the other parts of his body including the internal organs did not have any abnormality.

\section{Materials and Methods}

In both cases, the bird was anesthetized and sacrificed, and tumor was dissected out. The tissue was washed with phosphate-buffered saline, minced, and transferred into $0.5 \%$ collagenese B (Roche, Indianapolis, IN)/Hank's balanced salt solution. The tissue was incubated at $37^{\circ} \mathrm{C}$ for $1-3 \mathrm{~h}$ and mechanically dissociated. Ten milliliters of Dulbecco's Modified Eagle Medium (DMEM; Sigma, St. Louis, MO) supplemented with $36.7 \mathrm{mmol} / \mathrm{L}$ glucose, $10 \%$ $v / v$ heat-inactivated fetal bovine serum (Gibco BRL, Gaithersburg MD), 2\%v/v heat-inactivated chicken serum (Gibco BRL), and antibiotics $(100 \mathrm{U} / \mathrm{ml}$ penicillin $\mathrm{G}$, $100 \mu \mathrm{g} / \mathrm{ml}$ streptomycin sulfate) were added to the cells, and it was further dissociated by pipetting up and down. The 


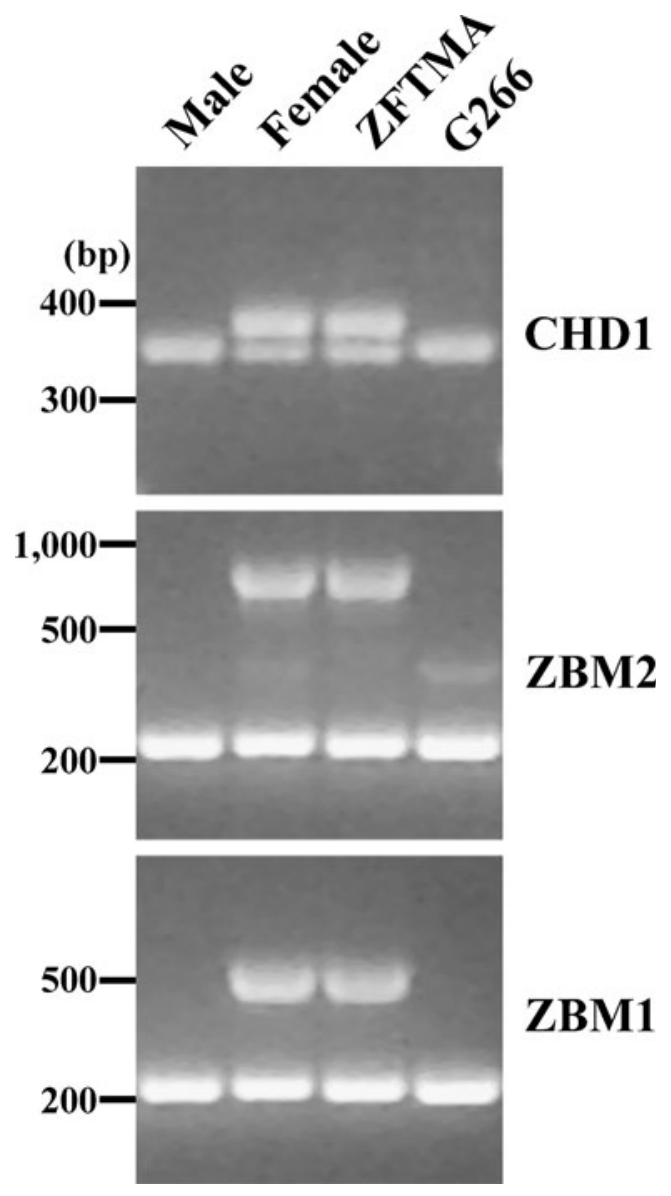

Figure 1. PCR sexing of ZFTMA and G266 cell lines. The PCR detected female specific bands (CHD1W, ZBM1/2 repetitive sequences) in control female and ZFTMA cell line. ZFTMA is female, and G266 is male.

cells were diluted with DMEM and plated out in a $100-\mathrm{mm}$ culture dish. The cultures were maintained at $37^{\circ} \mathrm{C}$ in $5 \%$ $\mathrm{CO}_{2}$ for 5-7 d, changing culture medium every day. Once the culture reached $100 \%$ confluence, the cells were passaged by harvesting with $0.05 \%$ Trypsin-1 mM EDTA
(Invitrogen, Carlsbad, CA) and re-plating at one-third to one-fifth of dilution. To isolate immortalized cells from normal cells in the population, we repeated the passage of cells every 2-3 d. ZFTMA cell line continued to grow over $300 \mathrm{~d}$ (over 100 passages), and G266 cell line grew over $185 \mathrm{~d}$ (over 60 passages) without any sign of senescence. The cell morphologies of these two cell lines were fibroblast-like.

\section{Results and Discussion}

Sexes of these two cell lines were further characterized by genomic PCR using four different primer sets (Fig. 1): $C H D 1-Z / W$ (Agate et al. 2004), TGW (data not shown; Runciman et al. 1999), and ZBM1 and ZBM2 (Itoh et al. 2008). All four cases confirmed the sex of ZFTMA cells as female and of G266 cells as male (Fig. 1). The doubling time of ZFTMA cells was $9.68 \mathrm{~h}$ (at $300 \mathrm{~d}$ of culture) and of G266 cells was $8.92 \mathrm{~h}$ (186 d culture), which was measured by counting the cell number using hemocytometer. Metaphase chromosome sets were prepared according to Itoh and Arnold (2005) and stained with 4',6-diamidino2-phenylindole (DAPI). Although the exact number of chromosomes has not been determined because of the difficulty in counting microchromosomes, ZFTMA cells were tetraploid and G266 cells were diploid (Fig. 2).

In vitro experiments using cell culture system offer many advantages, including advantageous experimental design and speed, reduction in use of animals, and ease of manipulation of gene expression. Cell culture can be a useful source of DNA, RNA, and protein due to high rates of cell proliferation. In some cases, it is critical to use a cell line from the species that is being investigated, for example, when testing the efficiency of RNAi before applying the RNAi molecule in vivo. Hopefully these first two zebra finch cell lines will offer experimental advantages to those studying this valuable model system.
Figure 2. Karyotype of ZFTMA and G266 cell lines. DAPI staining.
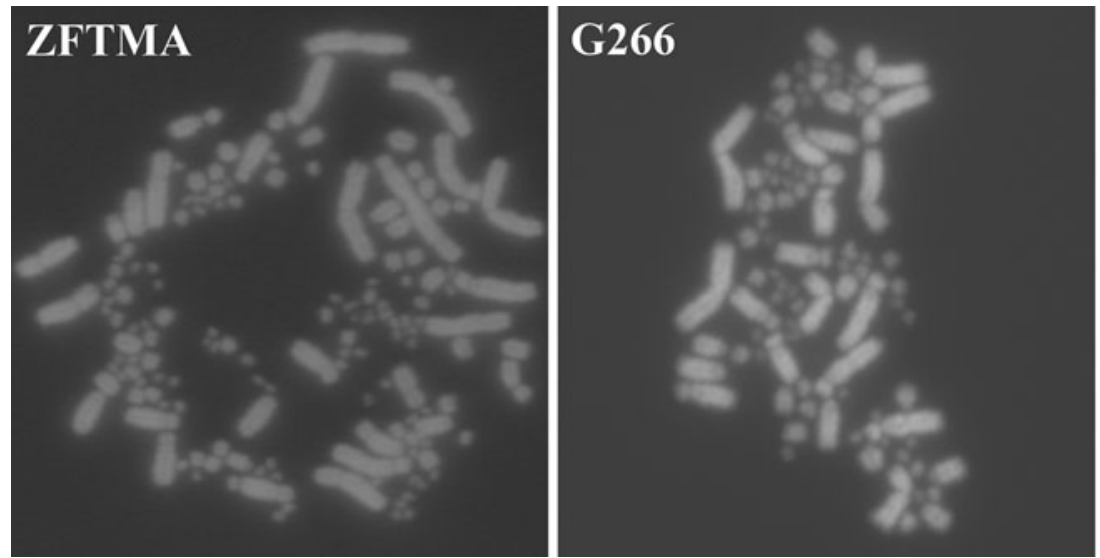
Acknowledgments This work was supported by NIH grant DC00217 to A.P. Arnold and a Yamada Science Foundation grant to Y. Itoh. We thank Hector Alcala and Kathy Kampf for assistance.

Open Access This article is distributed under the terms of the Creative Commons Attribution Noncommercial License which permits any noncommercial use, distribution, and reproduction in any medium, provided the original author(s) and source are credited.

\section{References}

Agate R. J.; Choe M.; Arnold A. P. Sex differences in structure and expression of the sex chromosome genes CHDIZ and
CHD1W in zebra finches. Mol. Biol. Evol. 21(2): 384-396; 2004.

Itoh Y.; Arnold A. P. Chromosomal polymorphism and comparative painting analysis in the zebra finch. Chomosom. Res. 13: 47-56; 2005.

Itoh Y.; Kampf K.; Arnold A. P. Molecular cloning of zebra finch W chromosome repetitive sequences: evolution of the avian W chromosome. Chromosoma. 117(2): 111-121; 2008.

Runciman D.; Zann R. A.; Murray N. D. A W-chromosome linked marker for gender identification in the zebra finch. Anim. Genet. 30(1): 66-67; 1999.

Warren W. C. et al. The genome of a songbird. Nature 464(7289): 757-762; 2010.

Ziegler H. P.; Marler P. (eds) Behavioral neurobiology of birdsong. Annals of the New York Academy of Sciences, New York, 1016; 2004. 